\title{
Carbon-11 Carboxylation of Trialkoxysilane and Trimethylsilane Derivatives Using $\left[{ }^{11} \mathrm{C}\right] \mathrm{CO} 2$
}

Salvatore Bongarzone, nicola raucci, Igor Fontana, Federico Luzi, Antony Gee

Submitted date: 16/12/2019 - Posted date: 20/12/2019

Licence: CC BY-NC-ND 4.0

Citation information: Bongarzone, Salvatore; raucci, nicola; Fontana, Igor; Luzi, Federico; Gee, Antony (2019):

Carbon-11 Carboxylation of Trialkoxysilane and Trimethylsilane Derivatives Using $\left[{ }^{11} \mathrm{C}\right] \mathrm{CO}$. ChemRxiv. Preprint. https://doi.org/10.26434/chemrxiv.11371086.v1

A novel carbon-11 carboxylation radiosynthesis methodology is described with the potential to be used to produce in vivo molecular imaging radiotracers for positron emission tomography. This is a simple and rapid method for incorporating carbon-11 labelling precursors such as $\left[{ }^{11} \mathrm{C}\right]$ carbon dioxide and $\left[{ }^{11} \mathrm{C}\right]$ methyl iodide into fluoride-activated silanes.

File list (1)

Silyl_5.docx (6.06 MiB)

view on ChemRxiv • download file 


\title{
Carbon-11 carboxylation of trialkoxysilane and trimethylsilane derivatives using $\left[{ }^{11} \mathrm{C}\right] \mathrm{CO}_{2}$
}

\author{
Salvatore Bongarzone, ${ }^{a}$ Nicola Raucci, ${ }^{a}$ Igor Camargo Fontana, ${ }^{a}$ \\ Federico Luzi and Antony D. Gee ${ }^{a}$
}

a'School of Biomedical Engineering \& Imaging Sciences, King's College London, King’s Health Partners, St Thomas' Hospital, London SE1 7EH, United Kingdom

\begin{abstract}
A novel carboxylation radiosynthesis methodology is described starting from cyclotron-produced $\left[{ }^{11} \mathrm{C}^{-\mathrm{CO}_{2}}\right.$ and fluoride-activated silane derivatives. Six $\left[{ }^{11} \mathrm{C}\right]$ carboxylic acids were obtained from their corresponding trimethylsilyl and trialkoxysilyl precursors in a one-pot labelling methodology. Radiochemical purity ranged from $18 \%$ to $93 \%$ within 12 minutes post $\left[{ }^{11} \mathrm{C}^{-} \mathrm{CO}_{2}\right.$ delivery with yields of 5-82\%.
\end{abstract}

Carbon-11 $\left({ }^{11} \mathrm{C}\right)$ is a short-lived radionuclide $\left(\mathrm{t}_{1 / 2}=20.4 \mathrm{~min}\right)$ commonly applied in positron emission tomography (PET) imaging. ${ }^{1}$ The isotopic substitution of carbon-12 for a carbon-11 atoms in bioactive molecules maintains the chemical and biological properties of the non-radioactive authologue, allowing the study of the pharmacokinetics and biodistribution of a wide range of biologically active molecules in living subjects. ${ }^{1}$

${ }^{11} \mathrm{C}$ is cyclotron-produced in the form of carbon dioxide $\left(\left[{ }^{11} \mathrm{C}\right] \mathrm{CO}_{2}\right)$ which can be directly incorporated into a variety of biologically relevant molecules, such as $\left[\right.$ carbonyl $-{ }^{11} \mathrm{C}$ ]carboxylic acids. ${ }^{2}$ Traditionally, aromatic $\left[{ }^{11} \mathrm{C}\right]$ carboxylic acids have been labelled directly from $\left[{ }^{11} \mathrm{C}\right] \mathrm{CO}_{2}$ using either $i$ ) Grignard reagents ${ }^{3}$ or ii) aromatic boronic esters as supporting reagents. ${ }^{4}$

However, these methodologies present some challenges which limit their wider application. For instance, the high reactivity of Grignard reagents is not well tolerated by many functional groups, limiting their utility to labelling functionally simple substrates. ${ }^{3}$ In addition, Grignard reagents are very sensitive to moisture or reaction with atmospheric $\mathrm{CO}_{2}$, even if great care is used in the storage and use of these reagents, leading to isotopic dilution of $\left[{ }^{11} \mathrm{C}\right] \mathrm{CO}_{2}$ and concomitant low molar activity $\left(\mathrm{A}_{\mathrm{m}}\right)$ of ${ }^{11} \mathrm{C}$-labelled products.

Compared to Grignard reagents, boronic esters have greater stability to atmospheric $\mathrm{CO}_{2}$ and moisture which broadens their use for radiolabelling aromatic and heteroaromatic compounds. ${ }^{4}$ However, the radiolabelling of the latter class of compounds (e.g. pyridyl, pyrazyl and thienyl boronic ester derivatives) is inconsistent and gives low- moderate radiochemical yields (RCY's 3\% - 69\%). ${ }^{4 a}$ 


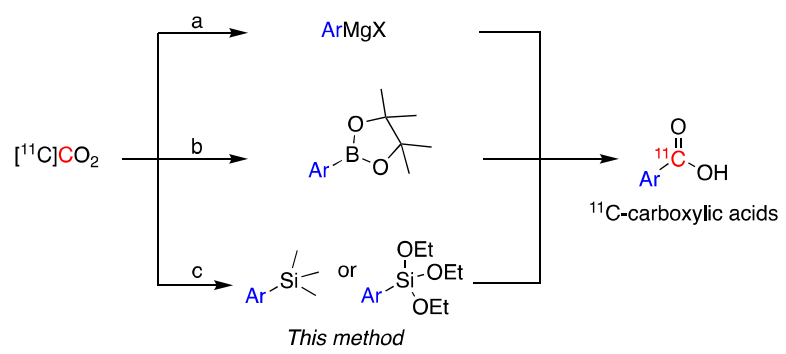

Scheme 1 Current methods for the preparation of aromatic $\left[{ }^{11} \mathrm{C}\right]$ carboxylic acids from $\left[{ }^{11} \mathrm{C}\right] \mathrm{CO}_{2}$ using: (a) Grignard reagents, (b) boronic esters and (c) trialkoxysilane and trimethylsilane derivatives - the latter used in this work.

Based on a search of the traditional synthetic chemistry literature, improved methods for the ${ }^{11} \mathrm{C}$ carboxylation of aryl and heteroaryl groups might be achieved by the use of trialkoxysilyl and trimethylsilyl derivatives via a so-called copper-catalysed desilylative carboxylation reaction. ${ }^{5}$ Arylsilanes reacted readily with a fluoride anion source, such as cesium fluoride (CsF), potassium fluoride (KF), tetramethylammonium fluoride $\left(\mathrm{Me}_{4} \mathrm{NF}\right)$ to form a pentavalent silicate. ${ }^{5-6}$ The pentavalent silicate was then converted in the presence of a copper catalyst to an arylcopper intermediate which reacted with non-radioactive $\mathrm{CO}_{2}$ in moderate to excellent yields $(27-99 \%){ }^{5-6}$ Varying the substitution patterns of the aromatic ring with electron-withdrawing or electron donating groups did not alter the efficiency of substrate carboxylation. ${ }^{5 a-c}$ Excellent results were also reported for the carboxylation of heteroaromatic compounds, such as thiophenyl, pyridyl and furanyl silane derivatives and their derivatization to ester products $(89 \%-93 \%){ }^{5 b, c}$

Compared to the traditional ${ }^{11} \mathrm{C}$-carboxylation methodologies, the use of silyl derivatives would provide greater air and moisture stability and therefore easier handling and storage. Moreover, trimethylsilyl and trialkoxysilyl precursors are readily obtained via a plethora of synthetic reagents: Grignard or organolitium reagents ${ }^{7}$ or functionalization of arylamides, ${ }^{8}$ arylacyl fluorides, ${ }^{9}$ aryl esters, ${ }^{10}$ aryl cyanides ${ }^{11}$ via transition-metals (Nickel, Copper, Ruthenium).

With the aim developing more robust and versatile ${ }^{11} \mathrm{C}$-carboxylation methodologies, we herein present the development of a novel ${ }^{11} \mathrm{C}$-carboxylation protocol involving the use of arylsilyl derivatives. The $\left[{ }^{11} \mathrm{C}\right]$ carboxylic acids were obtained in short synthesis times, with high molar activities and with broad applicability to range of trimethylsilane and trialkoxysilane derivatives. 


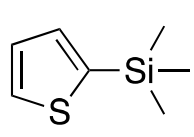

$1 \mathbf{a}$

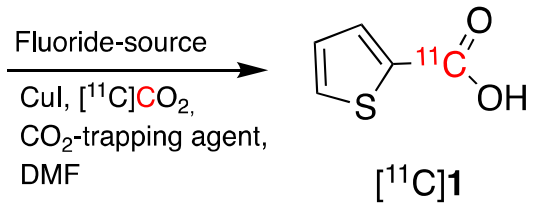

$\left[{ }^{11} \mathrm{C}\right] 1$

Scheme 2 Radiosynthetic approach to radiolabelled $\left[{ }^{11} \mathrm{C}\right]$ carboxylic acids from cyclotron-produced $\left[{ }^{11} \mathrm{C}\right] \mathrm{CO}_{2}$.

2-(Thienyl)trimethylsilane (1a, Scheme 2) was initially chosen as model substrate for cyclotronproduced $\left[{ }^{11} \mathrm{C}\right] \mathrm{CO}_{2}$ carboxylation reactions. Liu et al. reported that the combination of $\mathrm{CsF}$ and 18crown- 6 in the presence of $\mathrm{CO}_{2}(1 \mathrm{~atm})$ allowed the carboxylation of trimethylsilane derivatives in high yields. ${ }^{12}$ As a starting point, we applied the same approach of using CsF and 18-crown-6 (CsFcrown) in the presence of $\left[{ }^{11} \mathrm{C}\right] \mathrm{CO}_{2}$ to carboxylate 1a. However, when $1 \mathrm{a}(100 \mu \mathrm{mol}, 1$ equiv.) was reacted with $\left[{ }^{11} \mathrm{C}\right] \mathrm{CO}_{2}$ for 5 minutes at $100{ }^{\circ} \mathrm{C}$ in dimethylformamide (DMF), no $\left[{ }^{11} \mathrm{C}\right] \mathbf{1}$ was formed and the resulting $\left[{ }^{11} \mathrm{C}\right] \mathrm{CO}_{2}$ trapping efficiency (TE) was poor (entry 1, Table 1).

This might be due to the poor reactivity of the pentavalent silicate intermediate and/or the absence of any $\left[{ }^{11} \mathrm{C}\right] \mathrm{CO}_{2}$ trapping agent. The transmetallation of hypervalent silicates with copper catalysts $(10 \%)$ however have been shown to form arylcopper intermediates that readily react with non-radioactive $\mathrm{CO}_{2}{ }^{5 \mathrm{a}}$ Despite this finding, in our hands, the addition of $10 \% \mathrm{CuI}$ to the reaction mixture did not promote the formation $\left[{ }^{11} \mathrm{C}\right] \mathbf{1}$ (entry 2, Table 1). Moreover, the addition of a $\left[{ }^{11} \mathrm{C}\right] \mathrm{CO}_{2}$ trapping agent (1,8-diazabicyclo[5.4.0]undec-7-ene, DBU, 0.6 equiv.) did not favour the formation of $\left[{ }^{11} \mathrm{C}\right] \mathbf{1}$ either, although the TE increased from $6 \%$ to $77 \%$ (entry 1 versus 3 ).

We subsequently focused on selecting alternative fluoride sources, as CsF is highly hygroscopic and poorly soluble in organic solvents - even in the presence of 18 -crown-6, which might have hampered the formation of $\left[{ }^{11} \mathrm{C}\right] \mathbf{1}$. KF was investigated as a fluoride source as it has previously been used for the carboxylation of aryltrimethylsilanes, however, due its low reactivity KF in organic solvents the corresponding carboxylic acid derivative was only obtained with a low to moderate yield $(17-74 \%) .^{5 \text {, }}$ ${ }^{13}$ To increase the reactivity of KF in organic solvents, we opted to explore the use of the polyether kryptofix (K2.2.2), to form a $\mathrm{K}^{+}$- cryptand complex.

Interestingly, replacing CsF-crown with KF-K2.2.2 improved the formation of $\left[{ }^{11} \mathrm{C}\right] \mathbf{1}\left(100{ }^{\circ} \mathrm{C}, 5\right.$ minutes) giving radiochemical yields (RCY $)^{14}$ of $20 \%$ and high TE (96\%, entry 4).

In order to further increase the RCY of $\left[{ }^{11} \mathrm{C}\right] \mathbf{1}$, an optimization process was subsequently performed by modifying: $i$ ) the amount of fluoride source, $i i)$ the reaction temperature, $i i i)$ the amount of trapping reagent, $i v$ ) the amount of copper catalyst and $v$ ) the solvent. 
The effect of the equivalents of fluoride source was initially investigated.

Lowering the equivalents of the KF-K2.2.2 complex from 3 to 0.5 and 0.25 equivalents, and keeping the temperature at $100{ }^{\circ} \mathrm{C}$, enhanced the RCY of $\left[{ }^{11} \mathrm{C}\right] \mathbf{1}$ (20\% with 3 equiv., $25 \%$ with 0.5 equiv., and $28 \%$ with 0.25 equiv., entries 4-6). A similar trend was obtained at $140{ }^{\circ} \mathrm{C}(31 \%$ with 0.5 equiv., $37 \%$ with 0.25 equiv., entries $7-8$ ).

Additionally, we observed that higher temperatures favoured the formation of $\left[{ }^{11} \mathrm{C}\right] \mathbf{1}$ - either when 0.5 equivalents $\left(25 \%\right.$ at $100{ }^{\circ} \mathrm{C}$ versus $31 \%$ at $140{ }^{\circ} \mathrm{C}$, entries 5 and 7$)$ or 0.25 equivalents $\left(28 \%\right.$ at $100{ }^{\circ} \mathrm{C}$ versus $37 \%$ at $140{ }^{\circ} \mathrm{C}$, entries 6 and 8) of KF-K2.2.2 complex was used. Conversely, lowering the temperature to $70{ }^{\circ} \mathrm{C}$ had a detrimental effect, decreasing the TE and yield of $\left[{ }^{11} \mathrm{C}\right] \mathbf{1}$ (entry 9).

Increasing the amount of the trapping agent (DBU) from 0.6 to 0.9 equivalents did not alter the RCY of $\left[{ }^{11} \mathrm{C}\right] \mathbf{1}$ significantly ( $28 \%$ versus $24 \%$, entries 6 and 10 , respectively). Similarly, increasing the content of $\mathrm{CuI}$ from $10 \%$ to $20 \%$ did not markedly affect the RCY of $\left[{ }^{11} \mathrm{C}\right] \mathbf{1}(24 \%$, entry 11$)$.

The use of a different solvent was investigated. Using tetrahydrofuran (THF) instead of DMF, had a negative effect on reactivity, with the RCY of $\left[{ }^{11} \mathrm{C}\right] \mathbf{1}$ dropping to $1 \%$ (entry 12 ).

Optimal conditions were obtained when 1a $(100 \mu \mathrm{mol}, 1$ equiv.) was reacted with the cyclotronproduced $\left[{ }^{11} \mathrm{C}_{\mathrm{CO}_{2}}\right.$ at $140{ }^{\circ} \mathrm{C}$ in the presence of 0.25 equiv. of $\mathrm{KF}-\mathrm{K} 2.2 .2,10 \%$ of $\mathrm{CuI}$ and $\mathrm{DMF}$ (entry 8, Table 1).

Table 1 Reaction conditions and optimisation for the synthesis of $\left[{ }^{11} \mathrm{C}\right] \mathbf{1}$ using DBU as trapping agent. ${ }^{14}$

\begin{tabular}{|c|c|c|c|c|c|c|c|c|}
\hline Entry $^{a}$ & $\begin{array}{c}\text { Fluoride } \\
\text { source } \\
\text { (equiv.) }\end{array}$ & $\begin{array}{l}\text { Additive } \\
\text { (equiv.) }\end{array}$ & $\begin{array}{c}\text { DBU } \\
\text { (equiv.) }\end{array}$ & $\begin{array}{l}\mathrm{CuI} \\
(\%)\end{array}$ & Temp $\left({ }^{\circ} \mathrm{C}\right)$ & TE (\%) & $\begin{array}{c}\text { RCP of } \\
{\left[{ }^{11} \mathrm{C}\right] 1(\%)}\end{array}$ & $\begin{array}{c}\text { RCY of } \\
{\left[{ }^{11} \mathrm{C}\right] 1(\%)}\end{array}$ \\
\hline $1^{b}$ & $\mathrm{CsF}(3)$ & 18-crown-6 (3) & - & - & 100 & 6 & 0 & 0 \\
\hline $2^{b}$ & $\mathrm{CsF}(3)$ & 18-crown-6 (3) & - & 10 & 100 & 99 & 0 & 0 \\
\hline $3^{b}$ & $\mathrm{CsF}(3)$ & 18-crown-6 (3) & 0.6 & 10 & 100 & 77 & 0 & 0 \\
\hline $4^{b}$ & $\mathrm{KF}(3)$ & K2.2.2 (3) & 0.6 & 10 & 100 & 96 & 21 & 20 \\
\hline 5 & KF (0.5) & K2.2.2 (0.5) & 0.6 & 10 & 100 & $63 \pm 14$ & $41 \pm 9$ & $25 \pm 7$ \\
\hline 6 & $\mathrm{KF}(0.25)$ & K2.2.2 (0.25) & 0.6 & 10 & 100 & $52 \pm 5$ & $53 \pm 23$ & $28 \pm 12$ \\
\hline $7^{\mathrm{a}}$ & $\mathrm{KF}(0.5)$ & K2.2.2 (0.5) & 0.6 & 10 & 140 & 77 & 40 & 31 \\
\hline 8 & $\mathrm{KF}(0.25)$ & K2.2.2 (0.25) & 0.6 & 10 & 140 & $67 \pm 13$ & $55 \pm 7$ & $37 \pm 9$ \\
\hline $9^{b}$ & $\mathrm{KF}(0.25)$ & $\mathrm{K} 2.2 .2(0.25)$ & 0.6 & 10 & 70 & 37 & 0 & 0 \\
\hline 10 & $\mathrm{KF}(0.25)$ & K2.2.2 (0.25) & 0.9 & 10 & 100 & $86 \pm 5$ & $28 \pm 11$ & $24 \pm 10$ \\
\hline 11 & $\mathrm{KF}(0.25)$ & K2.2.2 (0.25) & 0.6 & 20 & 100 & $61 \pm 31$ & $44 \pm 26$ & $24 \pm 3$ \\
\hline $12^{\mathrm{b} / \mathrm{c}}$ & $\mathrm{KF}(0.25)$ & K2.2.2 (0.25) & 0.6 & 10 & 140 & 7 & 15 & 1 \\
\hline
\end{tabular}

Reaction conditions: $\left[{ }^{11} \mathrm{C}\right] \mathrm{CO}_{2}$ was bubbled in a solution of $1 \mathrm{a}(100 \mu \mathrm{mol}, 1$ equiv.), $\mathrm{DBU}(0.6-0.9$ equiv.), fluoride source $\mathrm{CsF}$ or $\mathrm{KF}$ (3-0.25 equiv.) and additive 18-crown-6 or K2.2.2 (3-0.25 equiv.) in DMF $(500 \mu \mathrm{L})$ at $0{ }^{\circ} \mathrm{C}$. Then, the reaction mixture was heated $\left(70-140{ }^{\circ} \mathrm{C}\right)$ for 5 minutes and after the system flushed with helium $(60 \mathrm{ml} / \mathrm{min})$ for 20 seconds. Subsequently, the temperature was reduced to $0{ }^{\circ} \mathrm{C}$ and the reaction quenched with a solution of $0.5 \%$ trifluoroacetic acid (TFA) in water and acetonitrile $\left(\mathrm{H}_{2} \mathrm{O}: \mathrm{MeCN}\right.$, $1: 1,1 \mathrm{~mL})^{a} n=3 .{ }^{b} n=1 ;{ }^{c} T H F$. 
Aiming to further increase the RCY of $\left[{ }^{11} \mathrm{C}\right] 1$, DBU was substituted with $\mathrm{BEMP}$ as $\mathrm{CO}_{2}$ trapping agent. Although no significant difference was observed at $100{ }^{\circ} \mathrm{C}(27 \%$ with BEMP, entry 1 , Table 2 versus $28 \%$ with DBU, entry 8 , Table $\mathbf{1}$ ), high yields of $\left[{ }^{11} \mathrm{C}\right] \mathbf{1}$ were obtained when the temperature was increased to $140{ }^{\circ} \mathrm{C}$ ( $82 \%$ with BEMP, entry 2 , Table 2 versus $37 \%$ with DBU, entry 8 , Table 1). Encouraged by these results, BEMP was used as trapping agent for the following experiments which initially focused on the effect of a shorter reaction times. Halving the reaction time from 5 to 2.5 minutes resulted in halving the RCY of $\left[{ }^{11} \mathrm{C}\right] \mathbf{1}$ (44\% at $2.5 \mathrm{~min}$. versus $82 \%$ at $5 \mathrm{~min}$., entries $2-3$, Table 2).

To understand the role of each reagent on the reaction mechanism, experiments were conducted with the omission of key reagents (KF, K2.2.2, BEMP, or CuI) from the reaction mixture. Removing BEMP or CuI, yielded $\left[{ }^{11} \mathrm{C}\right] \mathbf{1}$ but with a significantly lower RCY (5\% without BEMP and $15 \%$ without $\mathrm{CuI}$, entries 4-5). Notably, $\left[{ }^{11} \mathrm{C}\right] \mathbf{1}$ was not formed at all when $\mathrm{KF}$ or K2.2.2 were eliminated from the reaction mixture (entries 6 and 7, respectively). Similarly, when the amount of KF-K2.2.2 was halved, the RCY of $\left[{ }^{11} \mathrm{C}\right] \mathbf{1}$ was reduced three-fold (27\%, entry 8). These results highlight the primary role of the fluoride source as a desilylative reagent to promote the formation of a highly nucleophilic intermediate, which is stabilized by copper catalyst.

The effect of the solvent was also investigated during the optimisation of reaction conditions. The use of THF and acetonitrile $(\mathrm{MeCN})$ gave low or zero yields of $\left[{ }^{11} \mathrm{C}\right] \mathbf{1}(2 \%$ in THF and $0 \%$ in $\mathrm{MeCN}$, entries 9-10, Table 2).

Table 2 Reaction conditions and optimisation for the synthesis of $\left[{ }^{11} \mathrm{C}\right] \mathbf{1}$ using BEMP as trapping agent. ${ }^{14}$

\begin{tabular}{|c|c|c|c|c|c|c|c|c|c|}
\hline Entry $^{a}$ & $\begin{array}{c}\text { KF } \\
\text { (equiv.) }\end{array}$ & $\begin{array}{c}\text { K2.2.2 } \\
\text { (equiv. } \\
\text { ) }\end{array}$ & $\begin{array}{l}\text { BEMP } \\
\text { (equiv.) }\end{array}$ & $\begin{array}{l}\mathrm{CuI} \\
(\%)\end{array}$ & Solvent & $\begin{array}{c}\text { Temp } \\
\left({ }^{\circ} \mathrm{C}\right)\end{array}$ & TE (\%) & $\begin{array}{c}\text { RCP of } \\
{\left[{ }^{11} \mathrm{C}\right] 1(\%)}\end{array}$ & $\begin{array}{c}\text { RCY of } \\
{\left[{ }^{11} \mathrm{C}\right] 1(\%)}\end{array}$ \\
\hline 1 & 0.25 & 0.25 & 0.6 & 10 & DMF & 100 & $84 \pm 3$ & $33 \pm 15$ & $27 \pm 11$ \\
\hline 2 & 0.25 & 0.25 & 0.6 & 10 & DMF & 140 & $89 \pm 8$ & $93 \pm 6$ & $82 \pm 3$ \\
\hline $3^{\mathbf{b}}$ & 0.25 & 0.25 & 0.6 & 10 & DMF & 140 & $76 \pm 12$ & $58 \pm 9$ & $44 \pm 10$ \\
\hline 4 & 0.25 & 0.25 & - & 10 & DMF & 140 & $6 \pm 2$ & $95 \pm 0$ & $5 \pm 1$ \\
\hline 5 & 0.25 & 0.25 & 0.6 & - & DMF & 140 & $76 \pm 22$ & $24 \pm 18$ & $15 \pm 6$ \\
\hline $6^{c}$ & - & 0.25 & 0.6 & 10 & DMF & 140 & 40,30 & 0 & 0 \\
\hline $7^{d}$ & 0.25 & - & 0.6 & 10 & DMF & 140 & 48 & 0 & 0 \\
\hline 8 & 0.125 & 0.125 & 0.6 & 10 & DMF & 140 & $55 \pm 15$ & $47 \pm 9$ & $27 \pm 11$ \\
\hline 9 & 0.25 & 0.25 & 0.6 & 10 & THF & 140 & $12 \pm 5$ & $20 \pm 7$ & $2 \pm 1$ \\
\hline $10^{\mathrm{d}}$ & 0.25 & 0.25 & 0.6 & 10 & $\mathrm{MeCN}$ & 140 & 50 & 0 & 0 \\
\hline
\end{tabular}

Reaction conditions: $\left[{ }^{11} \mathrm{C}\right] \mathrm{CO}_{2}$ was bubbled in a solution of $1 \mathrm{a}(100 \mu \mathrm{mol}, 1$ equiv.), BEMP (0.6 equiv.), $\mathrm{KF}(0.125-0.25$ equiv. $)$, and $\mathrm{K} 2.2 .2(0.125-0.25$ equiv. $)$ in $\mathrm{DMF}(500 \mu \mathrm{L})$ at $0{ }^{\circ} \mathrm{C}$. Then, the reaction mixture was heated $\left(100-140{ }^{\circ} \mathrm{C}\right)$ for $2.5-5$ minutes and then the system flushed with helium $(60 \mathrm{ml} / \mathrm{min})$ for 20 seconds. Subsequently, the temperature was reduced to $0{ }^{\circ} \mathrm{C}$ and the reaction quenched a solution of $0.5 \%$ TFA in $\mathrm{H}_{2} \mathrm{O}: \mathrm{MeCN}(1: 1,1 \mathrm{~mL}) .{ }^{a} n=3 ;{ }^{b} 2.5$ minutes; ${ }^{c} n=2 ;{ }^{d} n=1$; 
The results presented in Table 1 and Table 2 show that the RCY of $\left[{ }^{11} \mathrm{C}\right] \mathbf{1}$ is maximized when 100 $\mu \mathrm{mol}$ of $1 \mathrm{a}$ is reacted with 0.6 equiv. of BEMP, 0.25 equiv. of KF-K2.2.2 and 0.1 equiv. of $\mathrm{CuI}$ in DMF for 5 minutes at $140{ }^{\circ} \mathrm{C}$ (entry 2, Table 2). Following this protocol, $A_{m}$ of $3.1 \pm 0.4 \mathrm{Gbq} / \mu \mathrm{mol}$ for $\left[{ }^{11} \mathrm{C}\right] 1$ was obtained at end of bombardment (EOB) - starting from $2.30 \pm 0.3 \mathrm{GBq}$ of $\left[{ }^{11} \mathrm{C} \mathrm{CO}_{2}\right.$.

Reaction conditions were subsequently kept constant whilst studying the substrate scope of additional trialkoxysilyl and trimethylsilyl compounds.

Initially, the effect of silyl substituents other than the trimethyl silyl moiety on the thienyl ring was explored using a triethoxysilyl substituent (triethoxy-2-thienylsilane, 1b, Table 3). Both precursors 1a and $\mathbf{1 b}$, yielded the corresponding [ $\left.{ }^{11} \mathrm{C}\right] \mathbf{1}$. However, the use of $\mathbf{1 b}$ resulted in lower RCY (51\%, entry 1, Table 3) compared with 1a $(\mathrm{RCY}=82 \%$, entry 2, Table 2).

Next, we directed our attention on radiolabelling other ${ }^{11} \mathrm{C}$-labelled aromatic carboxylic acids such as $\left[{ }^{11} \mathrm{C}\right]$ benzoic acid $\left(\left[{ }^{11} \mathrm{C}\right] \mathbf{2}\right.$, entries 2-3) and $\left[{ }^{11} \mathrm{C}\right]$ p-toluic acid $\left(\left[{ }^{11} \mathrm{C}\right] \mathbf{3}\right.$, entries 4-5) using trimethyl silyl (2a and 3a) and the triethoxysilyl ( $\mathbf{2} \mathbf{b}$ and $\mathbf{3 b}$ ) precursors. In contrast to that observed with $\left[{ }^{11} \mathrm{C}\right] \mathbf{1}$, the trimethyl silyl derivatives showed a different reactivity to triethoxysilyl analogues. Indeed, $\mathbf{2} \mathbf{b}$ and $\mathbf{3 b}$ produced the corresponding $\left[{ }^{11} \mathrm{C}\right]$ carboxylic acids in good yields $\left(\mathrm{RCY}\right.$ of $\left[{ }^{11} \mathrm{C}\right] 2=64 \%$, entry 3 ; RCY of $\left[{ }^{11} \mathrm{C}\right] \mathbf{3}=63 \%$, entry 5 ), whereas the trimethylsilyl derivatives, $\mathbf{2 a}$ and $\mathbf{3 a}$, did not form the desired products ( $\mathrm{RCY}=0 \%$ for $\left[{ }^{11} \mathrm{C}\right] \mathbf{2}$ and $\left[{ }^{11} \mathrm{C}\right] \mathbf{3}$, entries 2 and 4 , respectively). As expected, the low reactivity of benzyl-trimethylsilyl substrates was also observed using 1-chloro-4(trimethylsilyl)benzene (4a), yielding only small amounts of $\left[{ }^{11} \mathrm{C}\right] \mathbf{4}(5 \%$, entry 6$)$.

Further studies focused on non-aromatic silane precursors such as fluorene and alkyne derivatives (entries 7-10). The radiolabelling of a fluorene moiety (5a) was effective, producing $\left[{ }^{11} \mathrm{C}\right]$ fluorene-9carboxylic acid $\left(\left[{ }^{11} \mathrm{C}\right] \mathbf{5}\right)$ in moderate RCY (35\%, entry 7). The radiolabelling of prop-1-yn-1ylbenzene (6a) to $\left[{ }^{11} \mathrm{C}\right] 3$-phenylpropiolic acid $\left(\left[{ }^{11} \mathrm{C}\right] \mathbf{6}\right)$, instead, was ineffective at $140{ }^{\circ} \mathrm{C}$ (entry 8 ) and $100{ }^{\circ} \mathrm{C}$ (entry 9). However, lowering the temperature to $30{ }^{\circ} \mathrm{C}$ yielded $\left[{ }^{11} \mathrm{C}\right] \mathbf{6}$, although with low RCY (3\%, entry 10$)$.

Table 3 Radiolabelling aromatic ${ }^{11} \mathrm{C}$-carboxylic acids $\left(\left[{ }^{11} \mathrm{C}\right] \mathbf{1 - 6}\right)$ with $\left[{ }^{11} \mathrm{C}\right] \mathrm{CO}_{2}$ and silyl derivatives. ${ }^{14}$

\begin{tabular}{llllllll}
\hline Entry $^{\mathrm{a}}$ & Reagent & R & Product & Temp $\left({ }^{\circ} \mathrm{C}\right)$ & TE $(\%)$ & RCP $(\%)$ & RCY $(\%)$ \\
\hline
\end{tabular}




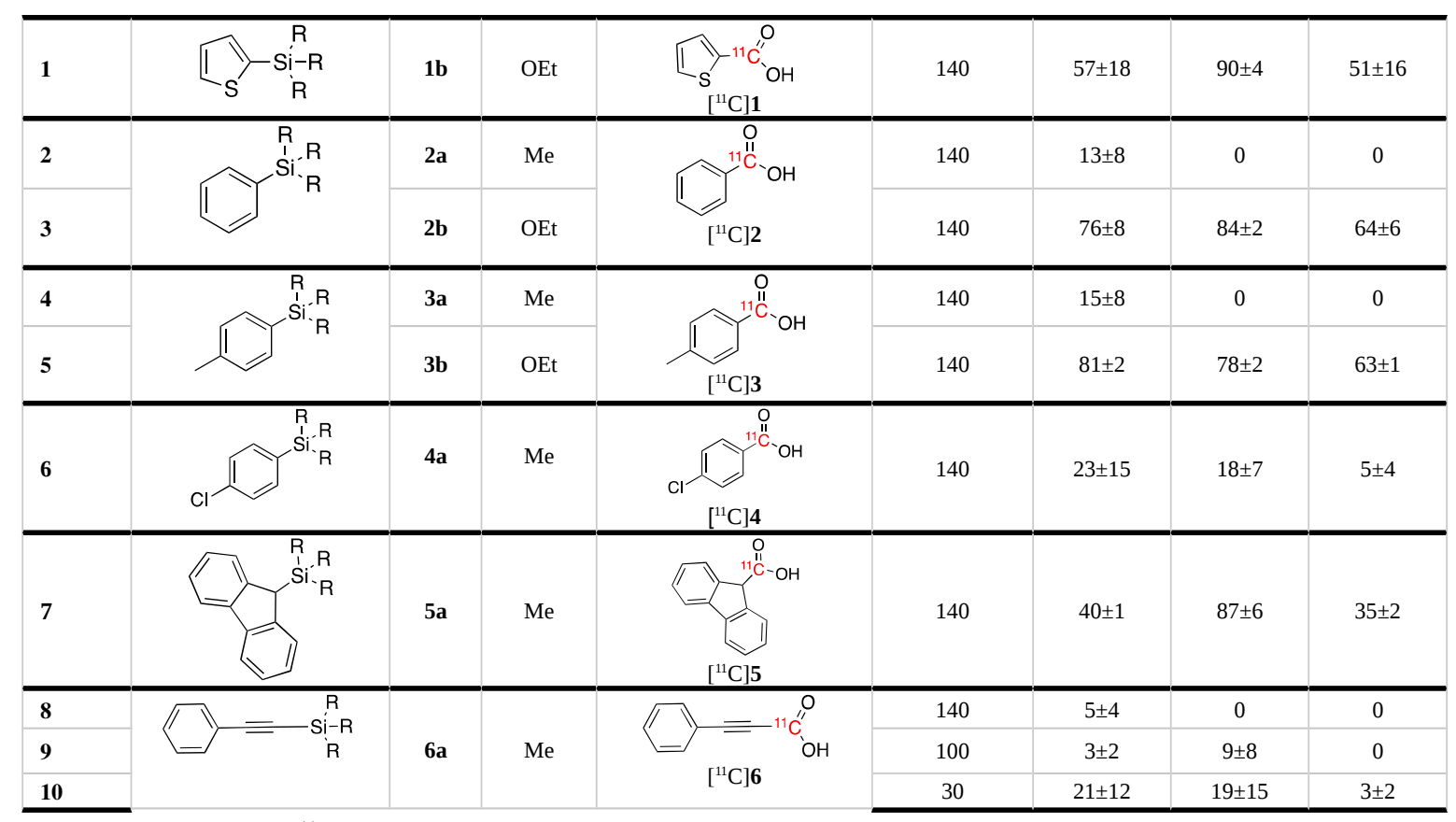

Reaction conditions: $\left[{ }^{11} \mathrm{C}\right] \mathrm{CO}_{2}$ was bubbled in a solution of $\mathbf{1 b}, \mathbf{2 a - b}, \mathbf{3 a - b}, \mathbf{4 a - 6 a}(0.1 \mathrm{mmol}, 1$ equiv.), BEMP $(0.6$ equiv.), $\mathrm{KF}\left(0.25\right.$ equiv.), and $\mathrm{K} 2.2 .2\left(0.25\right.$ equiv.) in DMF $(500 \mu \mathrm{L})$ at $0{ }^{\circ} \mathrm{C}$. Then, the reaction mixture was heated $\left(30-140{ }^{\circ} \mathrm{C}\right)$ for 5 minutes and then the system flushed with helium $(60 \mathrm{ml} / \mathrm{min})$ for 20 seconds. Subsequently, the temperature was reduced to $0{ }^{\circ} \mathrm{C}$ and the reaction quenched a solution of $0.5 \%$ TFA in $\mathrm{H}_{2} \mathrm{O}: \mathrm{MeCN}(1: 1,1 \mathrm{~mL}) .{ }^{a} n=3$;

To demonstrate that the arylcopper intermediates were obtained by the KF-K2.2.2 mediated desilylation of trimethylsilyl derivatives, we replaced $\left[{ }^{11} \mathrm{C}_{\mathrm{CO}_{2}}\right.$ by $\left[{ }^{11} \mathrm{C}\right] \mathrm{CH}_{3} \mathrm{I}$. $\left[{ }^{11} \mathrm{C}\right] 7$ was obtained by direct aromatic ${ }^{11} \mathrm{C}$-methylation of $\mathbf{1 a}$, with a RCP of of $16 \pm 4 \% \%(\mathrm{n}=3)$. Although this method has not been optimised here, we note a potential application of this strategy as an alternative route to produce a plethora of ${ }^{11} \mathrm{C}$-methylaromatic radiopharmaceuticals such as $(15 \mathrm{R})-\left[{ }^{11} \mathrm{C}\right] \mathrm{TIC},\left[{ }^{11} \mathrm{C}\right] \mathrm{MNQP}$, $\left[{ }^{11} \mathrm{C}\right] \mathrm{M}-\mathrm{MTEB},\left[{ }^{11} \mathrm{C}\right]$ celecoxib, $\left[{ }^{11} \mathrm{C}\right]$ cibbi-772, and $\left[{ }^{11} \mathrm{C}\right] \mathrm{UCB}-\mathrm{J}$ by direct aromatic ${ }^{11} \mathrm{C}$-methylation. ${ }^{2}$<smiles>C[Si](C)(C)c1cccs1</smiles>

$1 \mathrm{a}$

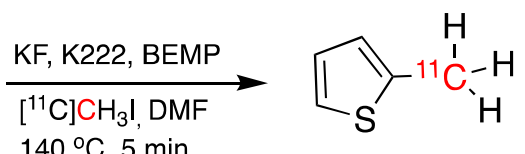

$\left[{ }^{11} \mathrm{C}\right] 7$

Scheme 3 Aromatic ${ }^{11} \mathrm{C}$-methylation of 1 a using $\left[{ }^{11} \mathrm{C}\right] \mathrm{CH}_{3}$ I to obtain $\left[{ }^{11} \mathrm{C}\right] 7$.

In summary, we have developed a novel carbon-11 reaction using cyclotron-produced $\left[{ }^{11} \mathrm{C}\right] \mathrm{CO}_{2}$ and aryltrimethylsilane and aryltrialkoxysilanes to obtain ${ }^{11} \mathrm{C}$-carboxylic acid derivatives. Aryltrimethylsilanes and aryltrialkoxysilanes are activated by a fluoride source (KF-K2.2.2) and copper catalyst which readily react with cyclotron-produced $\left[{ }^{11} \mathrm{C}^{-} \mathrm{CO}_{2}\right.$. We have also expanded the use 
of activated aryltrimethylsilanes as nucleophilic compounds for aromatic ${ }^{11} \mathrm{C}$-methylation using $\left[{ }^{11} \mathrm{C}_{\mathrm{CH}_{3}} \mathrm{I}\right.$. The application of silane-mediated ${ }^{11} \mathrm{C}$-carboxylation and ${ }^{11} \mathrm{C}$-methylation reactions using to relevant radiopharmaceuticals will be reported in due course.

\section{Acknowledgments}

This work was supported by Medical Research Council (MRC, MR/K022733/1) and European Commission, FP7-PEOPLE-2012-ITN (316882, RADIOMI). The authors acknowledge financial support from the Department of Health via the National Institute for Health Research (NIHR) Biomedical Research Centre at Guy's \& St Thomas' NHS Foundation Trust and King's College London and the Centre of Excellence in Medical Engineering funded by the Wellcome Trust and EPSRC under grant number WT 088641/Z/09/Z.

\section{References}

1(a) B. H. Rotstein, S. H. Liang, J. P. Holland, T. L. Collier, J. M. Hooker, A. A. Wilson and N. Vasdev, Chem Commun (Camb), 2013, 49, 5621-5629; (b) A. Sun, X. Liu and G. Tang, Front. Chem., 2017, 5, 124.

2(a) X. Deng, J. Rong, L. Wang, N. Vasdev, L. Zhang, L. Josephson and S. H. Liang, Angew. Chem., Int. Ed., 2019, 58, 2580-2605; (b) P. W. Miller, N. J. Long, R. Vilar and A. D. Gee, Angew. Chem., Int. Ed., 2008, 47, 8998-9033.

3(a) A. Pekošak, U. Filp, L. Rotteveel, A. J. Poot and A. D. Windhorst, J. Labelled Compd. Radiopharm., 2015, 58, 342-348; (b) D. Y. Tang, A. Lipman, G.-J. Meyer, C.-N. Wan and A. P. Wolf, J. Labelled Compd. Radiopharm., 1979, 16, 435440.

4(a) P. J. Riss, S. Lu, S. Telu, F. I. Aigbirhio and V. W. Pike, Angew. Chem., Int. Ed., 2012, 51, 2698-2702; (b) $\quad$ B. H. Rotstein, J. M. Hooker, J. Woo, T. L. Collier, T. J. Brady, S. H. Liang and N. Vasdev, ACS Med. Chem. Lett., 2014, 5, 668-672.

5(a) T. V. Q. Nguyen, W.-J. Yoo and S. Kobayashi, Asian J. Org. Chem., 2018, 7, 116-118; (b) X. Frogneux, N. von Wolff, P. Thuery, G. Lefevre and T. Cantat, Chemistry, 2016, 22, 2930-2934; (c) M. Yonemoto-Kobayashi, K. Inamoto and Y. Kondo, Chem. Lett., 2014, 43, 477-479; (d) T. Mita, H. Tanaka, K. Michigami and Y. Sato, Synlett, 2014, 25, 1291-1294.

6 L. A. Babadzhanova, N. V. Kirij and Y. L. Yagupolskii, J. Fluor. Chem., 2004, 125, 1095-1098.

7 A. S. Manoso, C. Ahn, A. Soheili, C. J. Handy, R. Correia, W. M. Seganish and P. Deshong, J Org Chem, 2004, 69, 8305-8314.

8 S.-C. Lee, L. Guo, H. Yue, H.-H. Liao and M. Rueping, Synlett, 2017, 28, 2594-2598.

9 X. Wang, Z. Wang and Y. Nishihara, Chem Commun (Camb), 2019, 55, 10507-10510.

10 L. Guo, A. Chatupheeraphat and M. Rueping, Angew. Chem. Int. Ed. Engl., 2016, 55, 11810-11813.

11 M. Tobisu, Y. Kita and N. Chatani, J . Am. Chem. Soc., 2006, 128, 8152-8153. 
12 B. Yu, P. Yang, X. Gao, Z. Z. Yang, Y. F. Zhao, H. Y. Zhang and Z. M. Liu, New J. Chem., 2017, 41, 9250-9255.

13 F. Effenberger and W. Spiegler, Chem. Ber., 1985, 118, 3900-3914.

14 , Radiochemical yield was calculated by multiplying TE and RCP. Radiochemical purity (RCP) of the crude product has been determined by analytical radio-HPLC. The trapping efficiency (TE) has been calculated as a ratio of the decay corrected radioactivity in the vial and the total radioactivity produced by the cyclotron. 


\title{
Carbon-11 carboxylation of trialkoxysilane and trimethylsilane derivatives using $\left[{ }^{11} \mathrm{C}\right] \mathrm{CO}_{2}$
}

\author{
Salvatore Bongarzone, ${ }^{a}$ Nicola Raucci, ${ }^{a}$ Igor Camargo Fontana, ${ }^{a}$ \\ Federico Luzi and Antony D. Gee
} aSchool of Biomedical Engineering \& Imaging Sciences, King's College London, King’s Health Partners, St Thomas'
Hospital, London SE1 7EH, United Kingdom

\section{Supplementary Information}

\section{General Method and Materials}

2-Thiophencarboxylic acid $(\mathbf{1}, 99 \%)$, benzoic acid $(\mathbf{2}, 99 \%)$, toluic acid $(\mathbf{3}, 99 \%)$, fluorene-9-carboxylic acid $(\mathbf{4}, 96 \%)$, phenylpropiolic acid $(\mathbf{5}, 99 \%)$, 4-chlorobenzoic acid $(\mathbf{6}, 99 \%)$, 2-methyltiophene $(\mathbf{7}, 99 \%)$, trimethyl-2-thienylsilane (1a, 97\%), triethoxy-2-thienylsilane (1b, 97\%), trimethyl(phenyl)silane (2a, 99\%), triethoxy(phenyl)silane (2b, 98\%), trimethyl-p-tolylsilane (3a, 97\%), triethoxy-p-tolylsilane (3b, 97\%), 9trimethylsilylfluorene (4a, 98\%), 1-phenyl-2-trimethylsilylacetilene $\quad(\mathbf{5 a}, \quad 99 \%), \quad$ 1-chloro4(trimethylsilyl)benzene (6a, 98\%), potassium fluoride (KF, 99\%), 4,7,13,16,21,24-hexaoxa-1,10diazabicyclo[8.8.8]hexacosane (K2.2.2, 99\%), 2-tert-Butylimino-2-diethylamino-1,3-dimethylperhydro1,3,2-diazaphosphorine

(BEMP,

$98 \%)$ 1,8-diazabicyclo[5.4.0]undec-7-ene (DBU, 98\%) copper(I) iodide (99\%), N,N-dimethylformamide (DMF, 99\%), 1,8-diazabicyclo[5.4.0]undec-7-ene (DBU, 98\%), Acetonitrile (ACN, 99\%) Tetrahydrofuran (THF, 99\%), Trifluoroacetic acid (TFA, 99\%), Acetonitrile (ACN, for HPLC $\geq 99 \%$ ), Water $\left(\mathrm{H}_{2} \mathrm{O}\right.$, for HPLC). All chemicals and dry solvents were purchased from Sigma-Aldrich, Alfa Aesar, Merck, Fisher Scientific and Acros Organics. TE, RCP, RCY and molar activity values are reported as mean \pm standard deviation.

\section{Carbon-11 Radiochemistry}

\section{Preparation of the Vial}

An oven-dried vial (KX Microwave Vials, $5 \mathrm{~mL}$ ) and a crimp cap (Fisherbrand, centre hole with $3.0 \mathrm{~mm}$ PTFE seal aluminium silver $20 \mathrm{~mm}$, part \# 10132712) were used. The vials were prepared in a glovebox 
(Plas-Labs, Inc. 815 PGB Series) under nitrogen atmosphere and controlled $\mathrm{CO}_{2}$ levels (lower than 30 ppm).

\section{$\left[{ }^{11} \mathrm{C}\right] \mathrm{CO}_{2}$ Production}

$\left[{ }^{11} \mathrm{C}_{\mathrm{CO}_{2}}\right.$ was produced using a Siemens $\mathrm{RD} 112$ cyclotron by the $11 \mathrm{MeV}$ proton bombardment of nitrogen $\left(+0.5 \% \mathrm{O}_{2}\right)$ gas via the ${ }^{14} \mathrm{~N}(\mathrm{p}, \alpha){ }^{11} \mathrm{C}$ reaction. The cyclotron-produced $\left[{ }^{11} \mathrm{C}\right] \mathrm{CO}_{2}$ was bubbled in a stream of helium gas with a flow rate of $60 \mathrm{~mL} / \mathrm{min}$ post target depressurisation directly into a reaction v-vial (time from end of bombardment $(\mathrm{EOB})$ to end of delivery $(\mathrm{EOD})=1$ minute and 50 seconds).

\section{Description of the system}

The set up was implemented on an Eckert \& Ziegler system (Modular-Lab Standard) and included two switching valves and a heating block. All gas transfer lines were fabricated from PTFE tubing (length: 10$30 \mathrm{~cm}$, O.D.: $0.79 \times 0.4$ in., I.D.: $1 / 32 \times 0.16$ in.). $\mathrm{A}_{2} \mathrm{O}_{5}$ trap and one-way valve (BRAUN, normally closed backcheck valve, part \# 415062) were placed before the vial. The outlet gas line of the vial was connected to a cartridge (Biosys Solutions Ltd, Fritted Empty MiniSpeed Cartridges, part \# 2447) filled with ascarite ${ }^{\circledR}$ (Sigma-Aldrich, 1310-73-2) to trap unreacted $\left[{ }^{11} \mathrm{C}\right] \mathrm{CO}_{2}$. A tedlar ${ }^{\circledR}$ gas waste bag was placed at the outlet of the ascarite's cartridge to prevent any gaseous emission.

\section{Description of the carbon-11 carboxylation}

A cyclotron beam current of $5 \mu \mathrm{A}$ was maintained for a bombardment time of 1 minute for all reaction optimization experiments producing $300 \mathrm{MBq}$ of carbon-11 at EOD.

$\left[{ }^{11} \mathrm{C}\right] \mathrm{CO}_{2}$ (carried by helium gas) was bubbled directly from the target into a reaction vial containing aryltrimethylsilane or aryltrialkoxysilanes and reagents described in Tables 1-3 at $0{ }^{\circ} \mathrm{C}$. The outlet gas line of the vial was connected to an Ascarite ${ }^{\circledR}$ cartridge. After the delivery of $\left[{ }^{11} \mathrm{C} \mathrm{CO}_{2}(1.75\right.$ minutes from end of bombardment) the temperature was increased to $30,70,100,140{ }^{\circ} \mathrm{C}$ for $2.5-5$ minutes. At five minutes, the system was flushed with helium $(60 \mathrm{ml} / \mathrm{min})$ for 20 seconds. Thereafter, the reaction was cooled at $0{ }^{\circ} \mathrm{C}$ and quenched with a solution of $0.5 \%$ trifluoroacetic acid TFA $\left(\mathrm{CF}_{3} \mathrm{COOH}\right)$ in $\mathrm{MeCN} / \mathrm{H}_{2} \mathrm{O}(1: 1,1 \mathrm{~mL})$. The amount of radioactivity in the Ascarite ${ }^{\circledR}$ and vial were measured (to determine the trapping efficiency, $\mathrm{TE}$ ), and an aliquot of the crude mixture analysed by radio-HPLC to determine the radiochemical purity, RCP.

\section{Molar Activity calculation of $\left[{ }^{11} \mathrm{C}\right] 1$}


Eleven samples of $\mathbf{1}$ at different concentrations $(1.15-0.011 \mu \mathrm{mol} / \mathrm{mL})$ were analysed by HPLC to obtain a calibration curve of the peak area (mAU*s) versus $\mu \mathrm{mol} / \mathrm{mL}$. The peak areas of $\mathbf{1}$ were averaged and plotted in function of the corresponding $\mu \mathrm{mol} / \mathrm{mL}$ (Figure S2).

$\left[{ }^{11} \mathrm{C}\right] \mathbf{1}$ was produced following the procedure of entry 2 (Table 2) by starting from $2.30 \pm 0.3 \mathrm{GBq}$ of $\left[{ }^{11} \mathrm{C}\right] \mathrm{CO}_{2}$. After quenching the reaction, $\left[{ }^{11} \mathrm{C}\right] \mathbf{1}$ was purified by semipreparative HPLC and the peak corresponding to $\left[{ }^{11} \mathrm{C}\right] \mathbf{1}$ collected.

The radioactivity in $1.00 \mathrm{~mL}$ of solution containing the purified $\left[{ }^{11} \mathrm{C}\right] \mathbf{1}$ was determined. An aliquot of purified $\left[{ }^{11} \mathrm{C}\right] \mathbf{1}(20 \mu \mathrm{L})$ was analysed by analytical radio-HPLC (Figure S3) and the UV peak corresponding to $\mathbf{1}$ was integrated. The area of the UV peak was used to determine the $\mu \mathrm{mol} / \mathrm{mL}$ of the associated ${ }^{12} \mathrm{C}$-carrier content for $\left[{ }^{11} \mathrm{C}\right] \mathbf{1}$ from the equation of the calibration curve. The molar activity $\left(\mathrm{A}_{\mathrm{m}}\right)$ of $\left[{ }^{11} \mathrm{C}\right] 1$ was calculated to be $3.1 \pm 0.4 \mathrm{GBq} / \mu \mathrm{mol}(\mathrm{n}=3)$.

\section{Description of the carbon-11 methylation to obtain $\left[{ }^{11} \mathrm{C}\right] 7$}

The $\left[{ }^{11} \mathrm{C}_{\mathrm{CO}_{2}}\right.$ was transferred in a stream of helium at $70 \mathrm{~mL} / \mathrm{min}$ to a GE TRCAERLab ${ }^{\circ}$ FX MeI module ( $\mathrm{t}_{\text {delivery }}=1$ minute and 50 seconds). $\left[{ }^{11} \mathrm{C}\right] \mathrm{CH}_{3} \mathrm{I}$ was produced by gas phase conversion from $\left[{ }^{11} \mathrm{C}\right] \mathrm{CO}_{2}$ and transferred in a vial containing $1 \mathrm{~mL}$ of DMSO.

A DMSO solution of $\left[{ }^{11} \mathrm{C}^{-} \mathrm{CH}_{3} \mathrm{I}(2-4 \mathrm{MBq})\right.$ was transferred into a reaction vial containing $\mathbf{1 a}(0.1 \mathrm{mmol}, 1$ equiv.), $\mathrm{KF}$ (0.25 equiv.), K2.2.2, (0.25 equiv.), BEMP (0.6 equiv.) and $\mathrm{CuI}(10 \%)$ in $500 \mu \mathrm{L}$ of DMF at 0 ${ }^{\circ} \mathrm{C}$. The temperature was then increased to $140{ }^{\circ} \mathrm{C}$ for 5 minutes. Thereafter, the reaction was cooled at 0 ${ }^{\circ} \mathrm{C}$ and quenched with a solution of $0.5 \%$ TFA in $\mathrm{MeCN} / \mathrm{H}_{2} \mathrm{O}$ 1:1. An aliquot of the crude mixture analysed by radio-HPLC to determine the radiochemical purity, RCP.

\section{Quality control of compounds $\left[{ }^{11} \mathrm{C}\right] 1-\left[{ }^{11} \mathrm{C}\right] 7$}

HPLC analysis was performed on an Agilent 1200 system equipped with a UV detector $(\lambda=254 \mathrm{~nm})$ and a $\beta+$-flow detector coupled in series. A reverse-phase column (Phenomenex Luna-C18, 4.6 x $150 \mathrm{~mm}, 5 \mu \mathrm{m}$ ) was used with a flow rate of $1 \mathrm{~mL} / \mathrm{min}$.

Identification of all radioactive products was confirmed by co-elution of $\left(\left[{ }^{11} \mathrm{C}\right] 1-\left[{ }^{11} \mathrm{C}\right] 7\right)$ with the corresponding non-radioactive compounds (1-7).

Compounds $\left[{ }^{11} \mathrm{C}\right] \mathbf{1}$ and $\left[{ }^{11} \mathrm{C}\right] \mathbf{7}$ 
The HPLC method was isocratic between 0-5.5 minutes $\left(\mathrm{CH}_{3} \mathrm{CN}+0.5 \%\right.$ TFA: $\mathrm{H}_{2} \mathrm{O}+0.5 \%$ TFA, 25:75), gradient between 5.5-6 minutes (25:75 to 0:100), isocratic between 6-9 minutes (0:100), gradient between 9-10 minutes $(0: 100$ to 25:75), isocratic between 10-13 minutes (25:75). $\left[{ }^{11} \mathrm{C}\right] \mathbf{1} \mathrm{t}_{\mathrm{R}}=5$ minutes and 20 seconds (Figure $\mathbf{S 1}$ ).

$\left[{ }^{11} \mathrm{C}\right] 7 \mathrm{t}_{\mathrm{R}}=8$ minutes and 40 seconds.

\section{Compound $\left[{ }^{11} \mathrm{C}\right] 2$}

The HPLC method was isocratic between 0-9 minutes $\left(\mathrm{CH}_{3} \mathrm{CN}+0.5 \%\right.$ TFA: $\mathrm{H}_{2} \mathrm{O}+0.5 \%$ TFA, 25:75), gradient between 9-10 minutes (25:75 to 0:100), isocratic between 10-13 minutes (0:100), gradient between 13-14 minutes (0:100 to 25:75) and isocratic between 14-17 minutes ( $25: 75$ ). $t_{R}=7$ minutes and 30 seconds.

\section{Compounds $\left[{ }^{11} \mathrm{C}\right] \mathbf{3}$ and $\left[{ }^{11} \mathrm{C}\right] \mathbf{5}$}

The HPLC method was isocratic between 0-5.5 minutes $\left(\mathrm{CH}_{3} \mathrm{CN}+0.5 \%\right.$ TFA: $\mathrm{H}_{2} \mathrm{O}+0.5 \%$ TFA, 35:65), gradient between 5.5-9 minutes (35:65 to 0:100), isocratic between 9-12 minutes (0:100), gradient between 12-13 minutes (0:100 to 35:65), isocratic between 13-16 minutes (35:65).

$\left[{ }^{11} \mathrm{C}\right] 3$ : $\mathrm{t}_{\mathrm{R}}=6$ minutes and 20 seconds.

$\left[{ }^{11} \mathrm{C}\right] 5$ : $\mathrm{t}_{\mathrm{R}}=7$ minutes and 7 seconds.

\section{Compound $\left[{ }^{11} \mathrm{C}\right] \mathbf{4}$}

The HPLC method was isocratic between 0-5.5 minutes $\left(\mathrm{CH}_{3} \mathrm{CN}+0.5 \%\right.$ TFA: $\mathrm{H}_{2} \mathrm{O}+0.5 \%$ TFA, 50:50), gradient between 5.5-9 minutes (50:50 to 0:100), isocratic between 9-12 minutes (0:100), gradient between 12-13 minutes (0:100 to 50:50), isocratic between 13-16 minutes (50:50).

$t_{R}=5$ minutes and 46 seconds.

\section{Compound $\left[{ }^{11} \mathrm{C}\right] \mathbf{6}$}

The HPLC method was isocratic between 0-5.5 minutes $\left(\mathrm{CH}_{3} \mathrm{CN}+0.5 \%\right.$ TFA: $\mathrm{H}_{2} \mathrm{O}+0.5 \%$ TFA, 45:55), gradient between 5.5-9 minutes (45:55 to 0:100), isocratic between 9-12 minutes isocratic (0:100), gradient between 12-13 minutes (0:100 to 45:55), isocratic between 13-16 minutes (45:55).

$t_{R}=5$ minutes and 30 seconds. 


\section{Semipreparative HPLC method for the purification of $\left[{ }^{11} \mathrm{C}\right] 1$.}

HPLC analysis was performed on an Agilent 1200 system equipped with a UV detector ( $\lambda=254 \mathrm{~nm}$ ) and a $\beta+$-flow detector coupled in series. A reverse-phase column (Phenomenex Luna-C18, 10 x $250 \mathrm{~mm}, 5 \mu \mathrm{m}$ ) was used with a flow rate of $4 \mathrm{~mL} / \mathrm{min}$.

The HPLC method was isocratic between 0-10.4 minutes $\left(\mathrm{CH}_{3} \mathrm{CN}+0.5 \%\right.$ TFA: $\mathrm{H}_{2} \mathrm{O}+0.5 \%$ TFA, 25:75), gradient between 10.4-11.8 minutes (25:75 to 0:100), isocratic between 11.8-17.7 minutes (0:100), gradient between 17.7-19.69 minutes (0:100 to 25:75), isocratic between 19.69-26 minutes (25:75). $\mathrm{t}_{\mathrm{R}}=11$ minutes and 48 seconds.
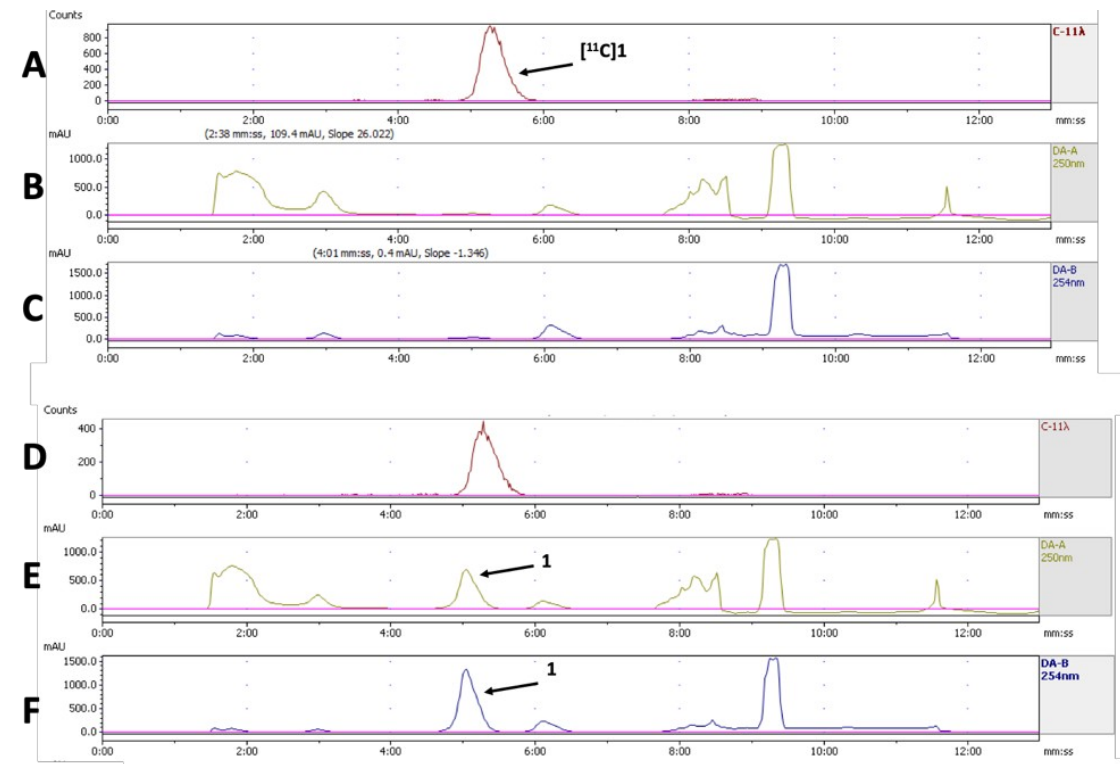

Fig. S1 A) Radio-HPLC chromatogram of crude $\left[{ }^{11} \mathrm{C}\right] \mathbf{1}$. B and C) UV chromatograms of crude $\left[{ }^{11} \mathrm{C}\right] \mathbf{1}$ at 250 and $254 \mathrm{~nm}$, respectively. D) Radio-HPLC chromatogram of crude $\left[{ }^{11} \mathrm{C}\right] \mathbf{1}$ co-injected with $\mathbf{1}$. E and F) UV chromatograms of crude $\left[{ }^{11} \mathrm{C}\right] \mathbf{1}$ co-injected with 1 at 250 and $254 \mathrm{~nm}$, respectively. The difference between UV peaks (retention time $\left(t_{R}\right)=5$ minutes and 7 seconds) and radioactivity peaks ( $t_{R}=5$ minutes and 20 seconds) is 13 seconds, consistent with the expected delay time between detectors (13 seconds). 


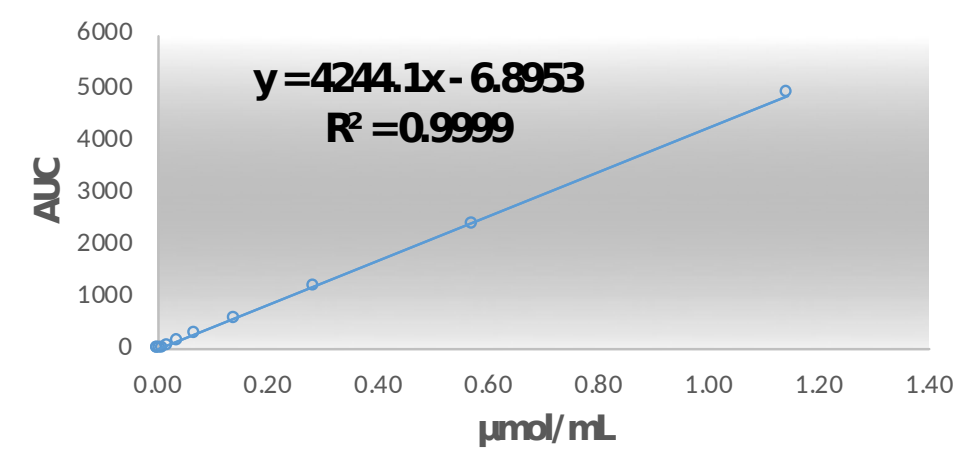

Fig. S2 Calibration Curve for 1.

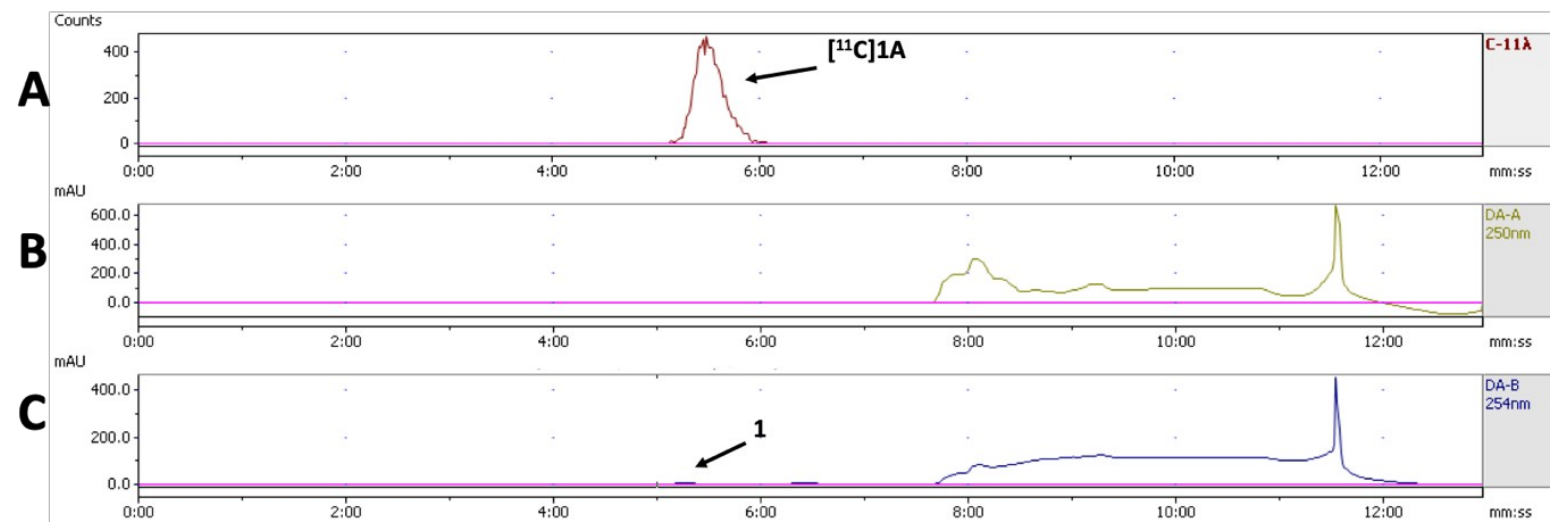

Fig. S3 A) Radio-HPLC chromatogram of HPLC-purified $\left[{ }^{11} \mathrm{C}\right] \mathbf{1}$. B and $\left.\mathbf{C}\right) \mathrm{UV}$ chromatograms of HPLCpurified $\left[{ }^{11} \mathrm{C}\right] \mathbf{1}$ at 250 and $254 \mathrm{~nm}$, respectively. The difference between UV peaks (retention time $\left(\mathrm{t}_{\mathrm{R}}\right)=5$ minutes and 15 seconds) and radioactivity peaks ( $t_{R}=5$ minutes and 28 seconds) is 13 seconds consistent with the expected delay time between detectors (13 seconds). 
